Article

\title{
Diversity of Ophiostomatoid Fungi Associated with Dendroctonus armandi Infesting Pinus armandii in Western China
}

\author{
Huimin Wang ${ }^{1}$, Tiantian Wang ${ }^{1}$, Ya Liu ${ }^{1}$, Fanyong Zeng ${ }^{2}$, Haifeng Zhang ${ }^{3}$, Cony Decock ${ }^{4}$, Xingyao Zhang ${ }^{1}$ and \\ Quan Lu ${ }^{1, * \mathbb{D}}$
}

check for

updates

Citation: Wang, H.; Wang, T.; Liu, Y.; Zeng, F.; Zhang, H.; Decock, C.; Zhang, X.; Lu, Q. Diversity of Ophiostomatoid Fungi Associated with Dendroctonus armandi Infesting Pinus armandii in Western China. J. Fungi 2022, 8, 214. https://doi.org/ $10.3390 /$ jof 8030214

Academic Editors: Samantha C. Karunarathna, Belle Damodara Shenoy, Patcharee Pripdeevech, Sumedha Madawala, Alvin M. C. Tang, Benjarong Karbowy-Thongbai, Asha Janadaree Dissanayake and Arun Kumar Dutta

Received: 30 January 2022

Accepted: 19 February 2022

Published: 22 February 2022

Publisher's Note: MDPI stays neutral with regard to jurisdictional claims in published maps and institutional affiliations.

Copyright: (c) 2022 by the authors. Licensee MDPI, Basel, Switzerland. This article is an open access article distributed under the terms and conditions of the Creative Commons Attribution (CC BY) license (https:// creativecommons.org/licenses/by/ $4.0 /)$.
1 Key Laboratory of Forest Protection of National Forestry and Grassland Administration, Institute of Forest Ecology, Environment and Nature Conservation, Chinese Academy of Forestry, Beijing 100091, China; wanghuimin@caf.ac.cn (H.W.); sstr94@163.com (T.W.); 13436862712@163.com (Y.L.); xyzhang@caf.ac.cn (X.Z.)

2 Chinese Academy of Forestry, Beijing 100091, China; zeng@caf.ac.cn

3 Longcaoping Forestry Bureau of Shaanxi Province, Foping County, Hanzhong 723401, China; zhangxinyi0302@163.com

4 Mycothèque de 1'Université Catholique de Louvain (BCCM/MUCL), Earth and Life Institute, Microbiology, B-1348 Louvain-la-Neuve, Belgium; cony.decock@uclouvain.be

* Correspondence: luquan@caf.ac.cn; Tel.: +86-13671215152

\begin{abstract}
Pinus armandii (P. armandii) is extensively abundant in western China and, as a pioneer tree, and prominently influences local ecology. However, pine forests in this region have been significantly damaged by Dendroctonus armandi (D. armandi) infestations, in close association with ophiostomatoid fungi. This study aimed to identify the diversity of ophiostomatoid fungi associated with $D$. armandi infesting P. armandii in western China. A total of 695 ophiostomatoid fungal strains were isolated from 1040 tissue pieces from $D$. armandi galleries and 89 adult beetles at four sites. In this study, based on multiloci DNA sequence data, as well as morphological and physiological characteristics, seven species belonging to five genera were identified including three known species, Esteyea vermicola, Graphium pseudormiticum and L. wushanense, two novel taxa, Graphilbum parakesiyea and Ophiostoma shennongense, and an unidentified Ophiostoma sp. 1. A neotype of Leptographium qinlingense. Ophiostoma shennongense was the dominant taxon (78.99\%) in the ophiostomatoid community. This study provides a valuable scientific theoretical basis for the occurrence and management of $D$. armandi in the future.
\end{abstract}

Keywords: Esteyea; Graphilbum; Graphium; Leptographium; Ophiostoma; taxonomy

\section{Introduction}

The ubiquitous yet diverse associations between insects and fungi have long evolved [1-3], while the interactions between beetles, microbes, and hosts have been well documented [4-10], showing a variety of ecological strategies [11-13]. The associations among Pinus spp., Dendroctonus spp. (Coleoptera, Curculionidae, Scolytinae), and ophiostomatoid fungi are among of the most significant types of hosts-beetles-mycobiota mutualism.

Pinus armandii (P. armandii) is a native and pioneer coniferous species on the Qinling Mountains in China [14] that has a significant role in local economy and ecology. However, P. armandii has been infested with Dendroctonus armandi (D. armandi) since it was first reported in 1932 [15]. D. armandi is an endemic beetle species that gregariously attacks 20- to 50-year-old healthy, P. armandii mainly in western China [16,17]. To date, in an area spanning more than 4000 ha, approximately half a million P. armandii trees have been decimated by this beetle $[18,19]$.

The bark beetle-associated mycobiota, particularly ophiostomatoid fungi (Ophiostomatales, Microascales, Ascomycota), has been extensively studied due to its diversity, pathogenicity, and mutualism $[20,21]$. Previous studies have demonstrated that most 
fungi associated with D. armandi belong to Alternaria, Trichoderma, Verticillium, and ophiostomatoid fungi $[18,22,23]$. To date, ten species have been assigned to the order Ophiostomatales (Leptographium qinlingensis, L. terebrantis, Leptographium sp., Leptographium sp1., Leptographium sp2., Ophiostoma brevicolle, O. floccosum, O. quercus, and Ophiostoma sp.), and Microascales (Ceratocystis polonica) [18,22-25]. However, the records of L. terebrantis and C. polonica are uncertain due to the lack of confirmatory molecular analysis reports [22,24]. The former is associated with many bark beetles that are only recorded in North America, while the latter is associated with Ips spp. infesting spruce [26-28].

Research on the diversity of ophiostomatoid fungi associated with D. armandi on $P$. armandii in China remains limited. There are no systematic studies, with only a few sporadic ophiostomatoid fungi reports [23-25]. Furthermore, the status of L. qinlingensis has been challenged, due to the absent type specimen, molecular analysis and limited morphological characteristics to prove that L. qinlingensis was a new species [24]. Therefore, the validity of $L$. qinlingensis should be considered if similar material is obtained from the same vector and host [29].

In this study, we explored the ophiostomatoid communities associated with $D$. armandi infecting P. armandii ecosystems in western China. Integrated morphological observations and multilocus DNA sequence data were used to analyze these communities. Our results provide insights into the communities of ophiostomatoid fungi associated with $D$. armandi in western China, which is a basic assignment for the subsequent study on the occurrence and management of D. armandi.

\section{Materials and Methods}

\subsection{Sample Collection and Fungi Isolation}

Samples including $D$. armandi adults and their breeding galleries were collected from infected P. armandii trees at four sites (Table 1) in western China from July to August 2018 and May to July 2019 (Figure 1). All four sites are pure forests of P. armandii with tree ages of approximately 40 years old and diameters of approximately 40 to $60 \mathrm{~cm}$. The trees used in this study showed signs of being dead or dying. The beetles were individually placed in sterilized Eppendorf tubes using tweezers, while their galleries were placed in sterile envelopes using a sterilized knife. Beetles and galleries were returned to the laboratory and stored at $4{ }^{\circ} \mathrm{C}$ for isolation within one week.

Beetles were crushed directly without superficial disinfection and transferred to a $2 \%$ malt extract agar (MEA: $20 \mathrm{~g}$ Biolab malt extract, $20 \mathrm{~g}$ Biolab agar, and $1000 \mathrm{~mL}$ deionized water). Galleries were cut into smaller tissue sections $(5 \times 5 \mathrm{~mm})$, disinfected with $1.5 \%$ sodium hypochlorite $(\mathrm{NaClO})$ for $60 \mathrm{~s}$, rinsed with sterile water three times, and placed in $9 \mathrm{~cm}$ petri dishes, as described by Seifert et al. [30]. All strains were purified using mycelium apex, and cultures were grown in the dark at $25^{\circ} \mathrm{C}$. According to the preliminary analysis of culture characteristics, representative strains of each morphotype were selected for further morphological and molecular studies. All fungal strains obtained in this study were maintained in the culture collection of the Chinese Academy of Forestry (CXY), and representative strains were maintained in the China Forestry Culture Collection Center (CFCC, part of the National Infrastructure of Microbial Resources) (Table 2).

\subsection{Morphological and Physiological Characteristics}

Pure cultures were incubated in the dark at $25^{\circ} \mathrm{C}$, culture morphology and growth status were observed daily, and the microstructures of reproduction forms were performed on $2 \%$ MEA media and incubated for 7 to 30 days. Microscope slides were prepared to observe the length and width of reproductive structures (such as conidiogenous apparatus, stipes cylindrical, conidiophore, and conidia) per strain using a BX51 OLYMPUS microscope with differential interference contrast. In total, 30 measurements were repeated for each morphological feature, and the statistics were presented as (min-) (mean-SD) -(mean + SD) (-max) (mean, average; SD, standard deviation; min, minimum; max, maximum). 

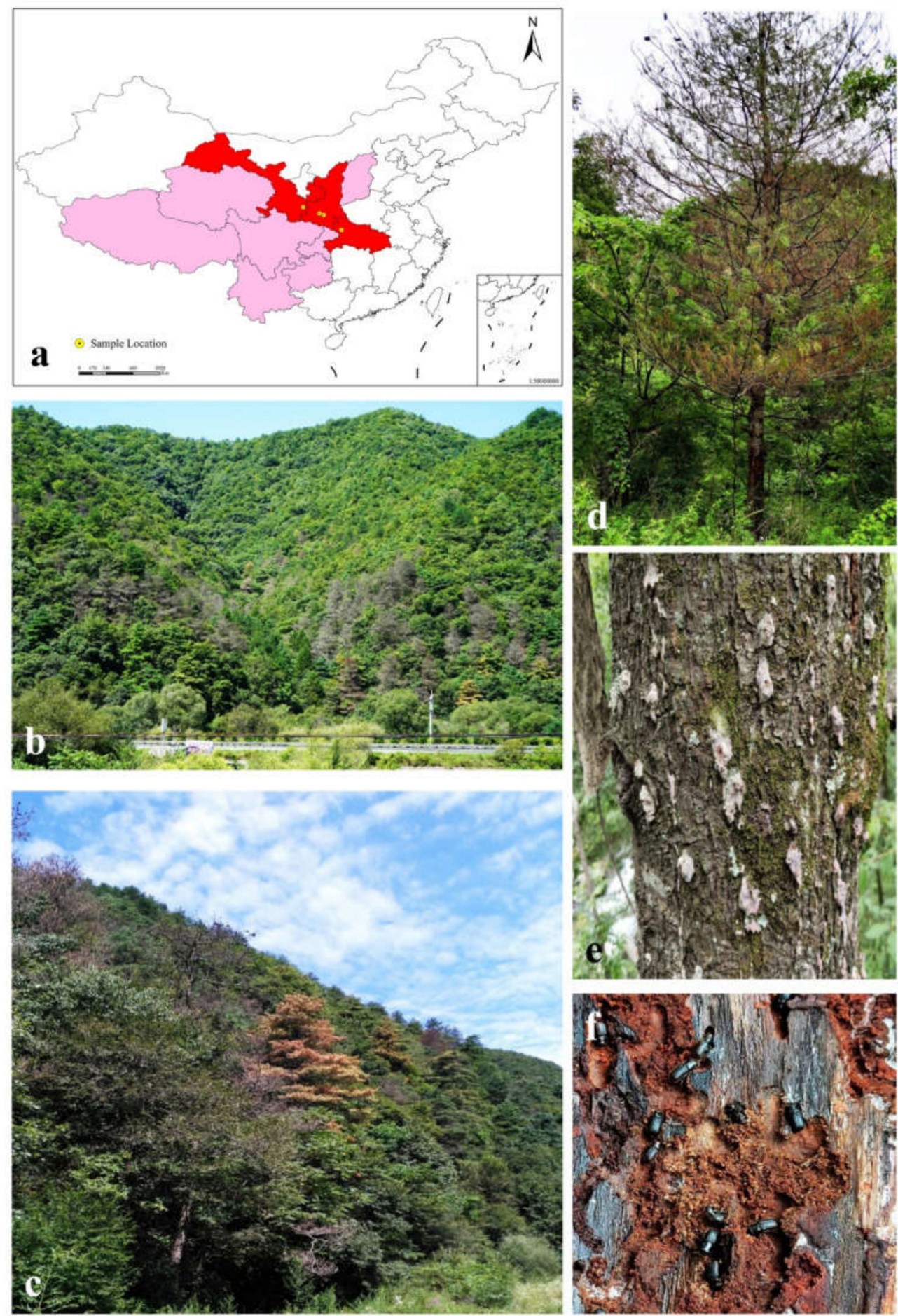

Figure 1. (a) Map showing the distribution of P. armandii and sample locations of D. armandi in China. (b-e) Disease symptoms of P. armandii infested by D. armandi and ophiostomatoid fungi in the Qinling Mountains of western China. (f) Adult D. armandi in galleries on P. armandii. 
Table 1. Basic information on the sample collection plots and samples obtained from P. armandii infested D. armandi in western China.

\begin{tabular}{|c|c|c|c|c|c|}
\hline Location & Longitude $\backslash$ Latitude & Altitude $\backslash \mathbf{m}$ & $\begin{array}{l}\text { No. of } \\
\text { Hosts }\end{array}$ & $\begin{array}{l}\text { No. of Tissue } \\
\text { Pieces }\end{array}$ & $\begin{array}{c}\text { No. of Adult } \\
\text { Beetles/Galleries }\end{array}$ \\
\hline $\begin{array}{c}\text { Shennongjia Forest Area, } \\
\text { Hubei Province }\end{array}$ & $\begin{array}{l}31^{\circ} 45^{\prime} 9^{\prime \prime} \mathrm{N} \\
110^{\circ} 28^{\prime} 34^{\prime \prime} \mathrm{E}\end{array}$ & 1821 & 5 & 381 & 30 \\
\hline $\begin{array}{c}\text { Dangchuan Forest Farm, } \\
\text { Gansu Province }\end{array}$ & $\begin{array}{l}34^{\circ} 20^{\prime} 53^{\prime \prime} \mathrm{N} \\
106^{\circ} 7^{\prime} 56^{\prime \prime} \mathrm{E}\end{array}$ & 1482 & 2 & 158 & 10 \\
\hline $\begin{array}{l}\text { Foping county, Shaanxi } \\
\text { Province }\end{array}$ & $\begin{array}{l}33^{\circ} 38^{\prime} 22^{\prime \prime} \mathrm{N} \\
107^{\circ} 58^{\prime} 26^{\prime \prime} \mathrm{E}\end{array}$ & 1769 & 2 & 131 & 12 \\
\hline $\begin{array}{l}\text { Huoditang Forest Form, } \\
\text { Shaanxi Province }\end{array}$ & $\begin{array}{l}33^{\circ} 27^{\prime} 56^{\prime \prime} \mathrm{N} \\
108^{\circ} 28^{\prime} 27^{\prime \prime} \mathrm{E}\end{array}$ & 2356 & 4 & 370 & 37 \\
\hline
\end{tabular}

For growth rate studies, representative strains were cultured in $90 \mathrm{~mm}$ diameter plates in the dark. A total of five replicate plates were included for each strain incubated at $5{ }^{\circ} \mathrm{C}$ intervals $\left(5\right.$ to $\left.35^{\circ} \mathrm{C}\right)$ for two weeks. The diameter of each colony was measured daily until the mycelium reached the edge of the MEA medium. Colony colors were described according to Rayner's color chart [31].

\subsection{DNA Extraction and Sequencing}

Before DNA extraction, the strains were grown on $2 \%$ MEA for $1-2$ weeks at $25{ }^{\circ} \mathrm{C}$ in the dark. The mycelia of purified strains were picked from the $60 \mathrm{~mm}$ diameter plates and placed into $2 \mathrm{~mL}$ sterile Eppendorf tubes. DNA extraction and purification were performed using the Plant Genomic DNA Kit (Invisorb Spin Plant Mini Kit, DP305, Tiangen, Beijing, China), following the manufacturer's protocol.

A total of five DNA regions were amplified for sequencing and phylogenetic analyses. The internal transcribed spacer regions (ITS1 and ITS2, including the $5.8 \mathrm{~S}$ gene) were amplified using the ITS1/ITS4 primer pair [32]; the nuclear ribosomal large subunit region (LSU) was amplified using the LROR/LR5 primer pair [33]; ITS2 and part of the ribosomal large subunit 28S (ITS2-LSU) were amplified using the ITS/LR3 primer pairs [32]; the $\beta$-tubulin (TUB2) gene was amplified using the BT2a/BT2b primer pair [34]; and the elongation factor1- $\alpha(E F 1-\alpha)$ gene was amplified using the EF1F/EF2R primer pair [35]. PCR reactions were conducted in $25 \mu \mathrm{L}$ volumes $(2.5 \mathrm{mM} \mathrm{MgCl} 2,1 \times$ PCR buffer, $0.2 \mathrm{mM}$ dNTP, $0.2 \mathrm{mM}$ of each primer, and 2.5 U Taq-polymerase enzyme), and PCR amplification was conducted using a thermocycler (Applied Biosystems, Foster City, CA, USA). The reaction conditions for the five DNA regions were similar to those described in the references for primer design. PCR products were cleaned with an MSB Spin PCR Apace Kit (250) following the manufacturer's instructions. All nucleotides were sequenced in both directions using a CEQ 2000 XL capillary automated sequencer (Beckman Coulter), and MEGA5.0 was used for splicing.

\subsection{Phylogenetic Analyses}

Preliminary identification of the obtained sequences based on ITS DNA fragments was performed using BLAST searches in the NCBI GenBank database. The related authentic sequences were downloaded for further phylogenetic analyses. Sequence alignment was performed online using MAFFT (http:/ / mafft.cbrc.jp/alignment/server/ accessed on 13 December 2021), implementing the iterative refinement method (FFT-NS-i setting) [36], and edited with MEGA5.0. The gaps were treated as the fifth base. Maximum likelihood (ML), maximum parsimony (MP), and Bayesian inference (BI) were used to assess these aligned sequences in phylogenetic analysis. 
Table 2. Representative strains of the ophiostomatoid fungi associated with D. armandi used for morphological and phylogenetic analysis and pathogenicity trials in this study.

\begin{tabular}{|c|c|c|c|c|c|c|}
\hline \multirow{2}{*}{ Group Taxon } & \multirow{2}{*}{ Name } & \multirow{2}{*}{ Strain No. } & \multirow{2}{*}{ Location } & \multicolumn{3}{|c|}{ GenBank No. } \\
\hline & & & & LSU/ITS/ITS2-LSU & TUB2 & TEF1- $\alpha$ \\
\hline \multirow{2}{*}{ Taxon 1} & Esteya vermicola & CFCC53942, CXY2518 & Shennongjia Forest Area, Hubei Province & MW465992 & MW690920 & - \\
\hline & & CFCC53924, CXY2516 T & Shennongjia Forest Area, Hubei Province & MW459985 & MW770444 & - \\
\hline \multirow[t]{2}{*}{ Taxon 2} & Graphilbum parakesiyea sp. & CFCC54514, CXY2539 & Foping County, Shaanxi Province & MW459986 & MW770445 & - \\
\hline & nov. & CFCC54515, CXY2540 & Foping County, Shaanxi Province & MW459987 & MW770446 & - \\
\hline \multirow[t]{4}{*}{ Taxon 3} & Graphium pseudormiticum & CFCC53943, CXY2519 & Shennongjia Forest Area, Hubei Province & MW459988 & - & MW690919 \\
\hline & & CFCC53937, CXY2510 & Dangchuan Forest Farm, Gansu Province & MW463377 & MW723023 & MW677124 \\
\hline & & CFCC53938, CXY2511 & Dangchuan Forest Farm, Gansu Province & MW463378 & MW723024 & MW677125 \\
\hline & & CFCC53923, CXY2512 & Dangchuan Forest Farm, Gansu Province & MW463379 & MW723025 & MW677126 \\
\hline \multirow{6}{*}{ Taxon 4} & Leptographium ainlingense & CFCC53939, CXY2513 & Dangchuan Forest Farm, Gansu Province & MW463380 & MW723026 & MW677128 \\
\hline & Leptographıum qinlingense & CFCC53940, CXY2514 & Dangchuan Forest Farm, Gansu Province & MW463381 & MW723027 & MW677129 \\
\hline & & CFCC53941, CXY2515 & Foping County, Shaanxi Province & MW463382 & MW723028 & MW677130 \\
\hline & & CFCC54521, CXY2541 & Foping County, Shaanxi Province & MW463383 & MW723029 & MW677131 \\
\hline & & CFCC54516, CXY2542 & Foping County, Shaanxi Province & MW463384 & MW723030 & MW677127 \\
\hline & & CFCC54524, CXY2543 & Huoditang Forest Farm, Shaanxi Province & MW463385 & MW690921 & - \\
\hline \multirow[t]{4}{*}{ Taxon 5} & L. wushanense & CFCC54525, CXY2544 & Huoditang Forest Farm, Shaanxi Province & MW463386 & MW690922 & - \\
\hline & & CFCC54526, CXY2545 & Huoditang Forest Farm, Shaanxi Province & MW463387 & MW690923 & - \\
\hline & & CFCC53921, CXY2501 T & Shennongjia Forest Area, Hubei Province & MW459989 & MW741822 & - \\
\hline & & CFCC53931, CXY2503 & Dangchuan Forest Farm, Gansu Province & MW459991 & MW741824 & - \\
\hline \multirow[t]{7}{*}{ Taxon 6} & Ophiostoma shennongense & CFCC53932, CXY2505 & Foping County, Shaanxi Province & MW459992 & MW741825 & - \\
\hline & & CFCC54528, CXY2534 & Dangchuan Forest Farm, Gansu Province & MW459993 & MW741826 & - \\
\hline & & CFCC54534, CXY2535 & Huoditang Forest Farm, Shaanxi Province & MW459994 & MW741827 & - \\
\hline & & CFCC54533, CXY2536 & Huoditang Forest Farm, Shaanxi Province & MW459995 & MW741828 & - \\
\hline & & CFCC53933, CXY2506 & Shennongjia Forest Area, Hubei Province & MW459996 & MW759042 & - \\
\hline & & CFCC53934, CXY2507 & Shennongjia Forest Area, Hubei Province & MW459997 & MW759043 & - \\
\hline & & CFCC53935, CXY2508 & Shennongjia Forest Area, Hubei Province & MW459998 & MW759044 & - \\
\hline \multirow[t]{4}{*}{ Taxon 7} & Ophiostoma sp. 1 & CFCC53936, CXY2509 & Shennongjia Forest Area, Hubei Province & MW459999 & MW759045 & - \\
\hline & & CFCC54535, CXY2531 & Foping County, Shaanxi Province & MW460000 & MW759046 & - \\
\hline & & CFCC54536, CXY2532 & Foping County, Shaanxi Province & MW460001 & MW759047 & - \\
\hline & & CFCC54540, CXY2533 & Huoditang Forest Farm, Shaanxi Province & MW460002 & MW759048 & - \\
\hline
\end{tabular}

CFCC: China Forestry Culture Collection Center, Beijing, China; _CXY (Culture Xingyao): Culture col 
ML analyses were conducted using RAxML v. 7.0.3, [37] under the GTR-GAMMA model. Supports for the nodes were estimated from 1000 bootstrap replicates. MP analyses were performed using PAUP*version $4.0 \mathrm{~b} 10$ [38]. A bootstrap analysis (1000 replicates using the neighbor-joining option) was performed to determine the support levels of the nodes. BI analyses were conducted using MrBayes v. 3.1.2 [39]. A total of four Markov chain Monte Carlo (MCMC) chains were run simultaneously from a random starting tree for five million generations, and samples were taken per 100 generations, resulting in 50,000 trees. Moreover, the first $25 \%$ of trees sampled were discarded during burn-in. Posterior probabilities were calculated by the retained trees. The topology of the resulting files was subsequently visualized using Figtree v.1.4.2 and Adobe Illustrator CS6.

\section{Results}

\subsection{Fungal Isolation}

In this study, 695 strains of ophiostomatoid fungi were isolated from 1040 tissue pieces from $D$. armandi galleries and 89 adult beetles at four sites (Tables 2 and 3). A total of 274 strains $(39.42 \%)$ and 421 strains $(60.58 \%)$ were isolated from the beetles and their galleries, respectively. Moreover, 280, 69, and 346 strains were obtained from the Hubei, Gansu, and Shaanxi provinces, respectively (Table 3 ).

Table 3. Strain numbers and percentage of various ophiostomatoid fungi isolated from D. armandi and their galleries in western China.

\begin{tabular}{|c|c|c|c|c|c|c|c|}
\hline \multirow[b]{2}{*}{ Taxon } & \multirow[b]{2}{*}{ Fungi Species } & \multicolumn{2}{|c|}{ No. of Isolates 2018} & \multicolumn{2}{|c|}{ No. of Isolates 2019} & \multirow[b]{2}{*}{$\begin{array}{l}\text { Total No. } \\
\text { Strains }\end{array}$} & \multirow[b]{2}{*}{$\begin{array}{c}\text { Percentage } \\
(\%)\end{array}$} \\
\hline & & $\begin{array}{l}\text { Shennongjia } \\
\text { Forest Area }\end{array}$ & $\begin{array}{l}\text { Dangchuan } \\
\text { Forest Farm }\end{array}$ & $\begin{array}{l}\text { Foping } \\
\text { County }\end{array}$ & $\begin{array}{l}\text { Huoditang } \\
\text { Forest Farm }\end{array}$ & & \\
\hline Taxon 1 & Esteyea vermicola & 1 & 0 & 0 & 0 & 1 & 0.14 \\
\hline Taxon 2 & Graphilbum parakesiyea & 2 & 0 & 15 & 8 & 25 & 3.60 \\
\hline Taxon 3 & Graphium pseudormiticum & 1 & 0 & 0 & 0 & 1 & 0.14 \\
\hline Taxon 4 & Leptographium qinlingensis & 2 & 24 & 31 & 5 & 62 & 8.92 \\
\hline Taxon 5 & L. wushanense & 0 & 0 & 0 & 34 & 34 & 4.89 \\
\hline Taxon 6 & Ophiostoma shennongensis & 266 & 42 & 27 & 215 & 549 & 78.99 \\
\hline \multirow[t]{2}{*}{ Taxon 7} & Ophiostoma sp. 1 & 6 & 3 & 4 & 9 & 22 & 3.17 \\
\hline & Total no. strains & 280 & 69 & 77 & 269 & 695 & \\
\hline
\end{tabular}

Growth rates, colony characteristics, and ITS sequence BLAST results were used for preliminary sorting and identification. These strains were distributed across five genera (Esteya, Graphilbum, Leptographium, Ophiostoma in the Ophiostomatales, and Graphium in the Microascales) and seven tentative species/groups (Taxon 1 to 7; Table 2). A total of 30 representative strains were selected for subsequent morphological and phylogenetic analyses.

\subsection{DNA Sequencing and Phylogenetic Analyses}

Phylogenetic analyses of the ITS, ITS2-LSU, LSU, TUB2, and TEF1- $\alpha$ gene regions were used to identify the genera/species and the genetic diversity within ophiostomatoid fungi $[29,40,41]$. Overall, one to eight strains were selected for each tentative species (Taxa $1-7)$ to construct the phylogenetic trees. The topologies generated by the ML, MP, and BI analyses were highly concordant, and phylograms obtained by ML were presented for all individual datasets, with branch supports obtained from MP and BI analyses.

Esteya (Taxon 1) and Graphium (Taxon 3) were each represented by a single strain. The two combined datasets (LSU+TUB2 and LSU+TEF1- $\alpha$ ) for Taxon 1 and Taxon 3 consisted of 1198 and 1114 characters (including gaps), respectively, grouped with Esteya vermicola and Graphium pseudormiticum (Supplementary Figures S1 and S2).

The remaining 28 representative strains were distributed in three major clades by phylogenetic inferences based on the ITS and ITS-LSU data sets, including Ophiostoma s. str, Leptographium s. l, and Graphilbum s. str. 
Taxon 2 was represented by three (Table 2) of the 25 strains (Table 3). It formed a wellsupported clade in both ITS and TUB2 based phylogenies, closely related to Graphilbum kesiyea but distinct (Figures 2 and 3); hence its recognition as a distinct species.

Taxon 4 included 62 strains (Table 3), while Taxon 5 included 34 strains (Table 3), with 11 representative strains (Table 2) belonging to the Leptographium lundbergii complex in the ITS2-LSU phylogenetic analyses (Figure 4). Additionally, eight strains (Table 2) of Taxon 4 formed a distinct and well-supported clade based on the TUB2 dataset (Figure 5). However, ITS2-LSU and TEF1- $\alpha$ based phylogenetic inferences revealed that these eight strains clustered together with L. qinlingensis with high support (Figures 4 and 6). There was no TUB2 sequence for $L$. qinlingensis prior to this. L. qinlingensis is a nom. inval., because of the lack of type specimen.

Taxon 5 grouped with Taxon 4 in the L. lundbergii complex and three representative strains of Taxon 5 grouped with L. wushanense, as defined by Pan et al. [42], based on ITS2-LSU and TUB2 phylogenetic analyses (Figures 4 and 5).

Taxon 6 included 549 strains (Table 3), seven of which (Table 2) were included in the phylogenetic analyses and clustered in the Ophiostoma clavatum complex. A total of seven (Table 2) of the 22 strains (Table 3) of Taxon 7 resided outside any recognized species complexes (Figure 2). The analysis of ITS and TUB2 sequences (Figures 2 and 7) showed that Taxon 6 formed a well-supported clade close to, yet distinct from, the ex-type sequences of $O$. clavatum. Meanwhile, Taxon 7, nested in the vicinity of O. aggregatum, forming a clade related to, yet distinct in the ITS and TUB2 phylogenetic trees (Figures 2 and 8). Hence, these strains in Taxon 6 and Taxon 7 were interpreted as belonging to two distinct, undescribed Ophiostoma species.

\subsection{Morphology and Taxonomy}

A total of three of the seven taxa identified in the present study were interpreted as undescribed species. These included one species of Graphilbum (Taxon 2) and two species of Ophiostoma (Taxa 6 and 7). However, no reproductive structures were observed for Taxon 7 on the different media used in this study; thus, we have elected to refrain from describing this taxon at this time. L. qinlingense was recollected during this study, and the name is revalidated by designation of a Neotype.

Taxonomy.

Graphilbum parakesiyea T. Wang \& Q. Lu sp. nov. Figure 9.

MycoBank: MB838526. kesiyea.

Etymology: 'parakesiyea' (Latin), refers to the phylogenetic affinities to Graphilbum

Type: China, Hubei Province, galleries of Dendroctonus armandi in Pinus armandii, Aug. 2018, TT Wang, holotype CXY2516, ex-type CFCC53924 = CXY2516.

Description: Sexual state not observed.

Asexual morph: hyalorhinocladiella-like. Conidiophores arising directly from the mycelium, simple or loosely branched, reduced to conidiogenous cells; conidiogenous cells aseptate or sparsely septate, thin-walled, with a rounded apex, hyaline (17.8-) 32.2-80 $(-116.3) \times(1.2-)$ 1.6-2.3 (-2.8) $\mu \mathrm{m}$. Conidia hyaline, single-celled, aseptate, smooth, clavate to elliptical with obtuse ends, (4.6-) 4.9-5.6 (-6.2) × (1.9-) 2.0-2.7 (-3.2) $\mu \mathrm{m}$.

Culture Characteristics: Colonies grew rapidly on $2 \%$ MEA, attaining $90 \mathrm{~mm}$ days at $30{ }^{\circ} \mathrm{C}$ in the dark, while, with appressed hyphae, colonies are white with a smooth margin. The optimum growth temperature is $30^{\circ} \mathrm{C}$; however, it can grow from $5{ }^{\circ} \mathrm{C}$ to $35^{\circ} \mathrm{C}$.

Known substrate and hosts: Galleries and adults of Dendroctonus armandi in Pinus armandii.

Known insect vectors: Dendroctonus armandi.

Known distribution: Hubei and Shaanxi provinces, China. 


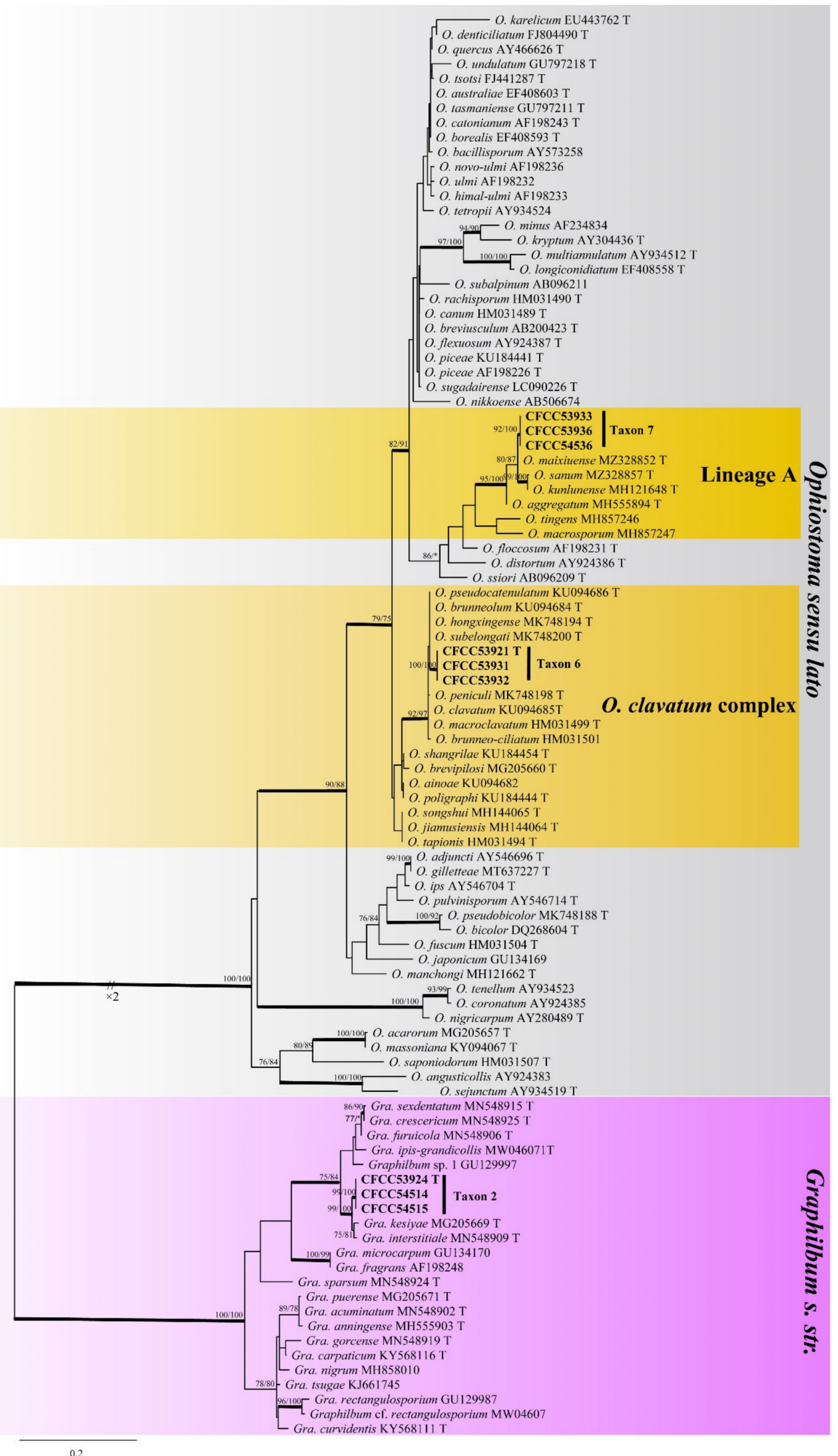


Figure 2. ML tree of Ophiostoma sensu lato and Graphilbum s. str. (Taxa 2, 6, and 7) generated from the ITS sequence data. Novel sequences obtained in this study are presented in bold typeface. Bold branches indicate posterior probability values $\geq 0.9$. Bootstrap values $\geq 70 \%$ for ML and MP are indicated above branches. Bootstrap values $<70 \%$ are indicated by ${ }^{*}$. Strains representing ex-type sequences are marked with ' $\mathrm{T}$ '.

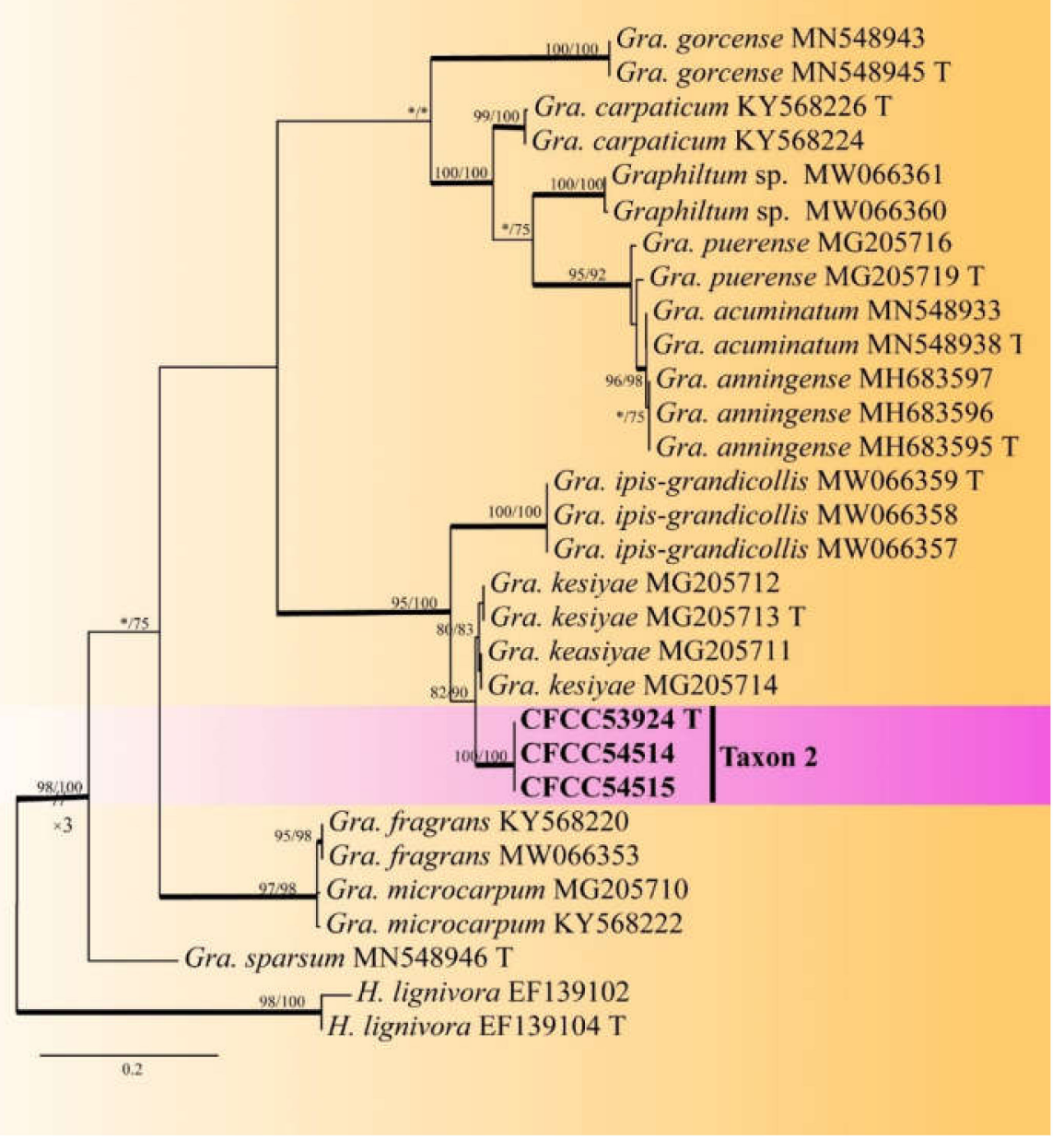

Figure 3. ML tree of Graphilbum s. str. generated from the TUB2 sequence data. Novel sequences obtained in this study are presented in bold typeface. Bold branches indicate posterior probability values $\geq 0.9$. Bootstrap values $\geq 70 \%$ for $\mathrm{ML}$ and $\mathrm{MP}$ are indicated above branches. Bootstrap values $<70 \%$ are indicated by ${ }^{*}$. Strains representing ex-type sequences are marked with ' $\mathrm{T}$ '.

Additional specimens examined: CHINA, Shaanxi Province, Foping country, galleries, and adults of Dendroctonus armandi in Pinus armandii, May to July 2019, TT Wang, CFCC $54514=$ CXY2539, CFCC 54515 = CXY2540.

Notes: Graphilbum parakesiyea is characterized by hyalorhinocladiella-like asexual morph. Phylogenetic analysis (Figures 2 and 3) revealed that Gra. parakesiyea is closely related to Gra. kesiyea. Graphilbum parakesiyea can be distinguished from Gra. kesiyea by their conidiogenous cells; conidiogenous cells of Gra. kesiyea are longer than that of Gra. parakesiyea, viz. 38-101.5 $\mu \mathrm{m}$ and 32.2-80 $\mu \mathrm{m}$, respectively. The two species also differ in their optimal growing temperatures of $25^{\circ} \mathrm{C}$ and $30^{\circ} \mathrm{C}$, respectively [43]. Furthermore, Gra. kesiyea was isolated from Pinus kesiya infected by Polygraphus aterrimus and Polygraphus szemaoensis [43], while Gra. parakesiyea was isolated from P. armandii infected with $D$. armandi.

Leptographium qinlingense (M. Tang) T. Wang \& Q. Lu comb. nov. Figure 10. 
三 Ophiostoma qinlingensis Tang, journal of Huazhong Agricultural University 23:5. 2004.

Type: no specified. Neotype: China, Shaanxi Province, galleries of Dendroctonus armandi in Pinus armandii, June 2019, TT Wang, neotype designated here CFCC53941 = CXY2515.

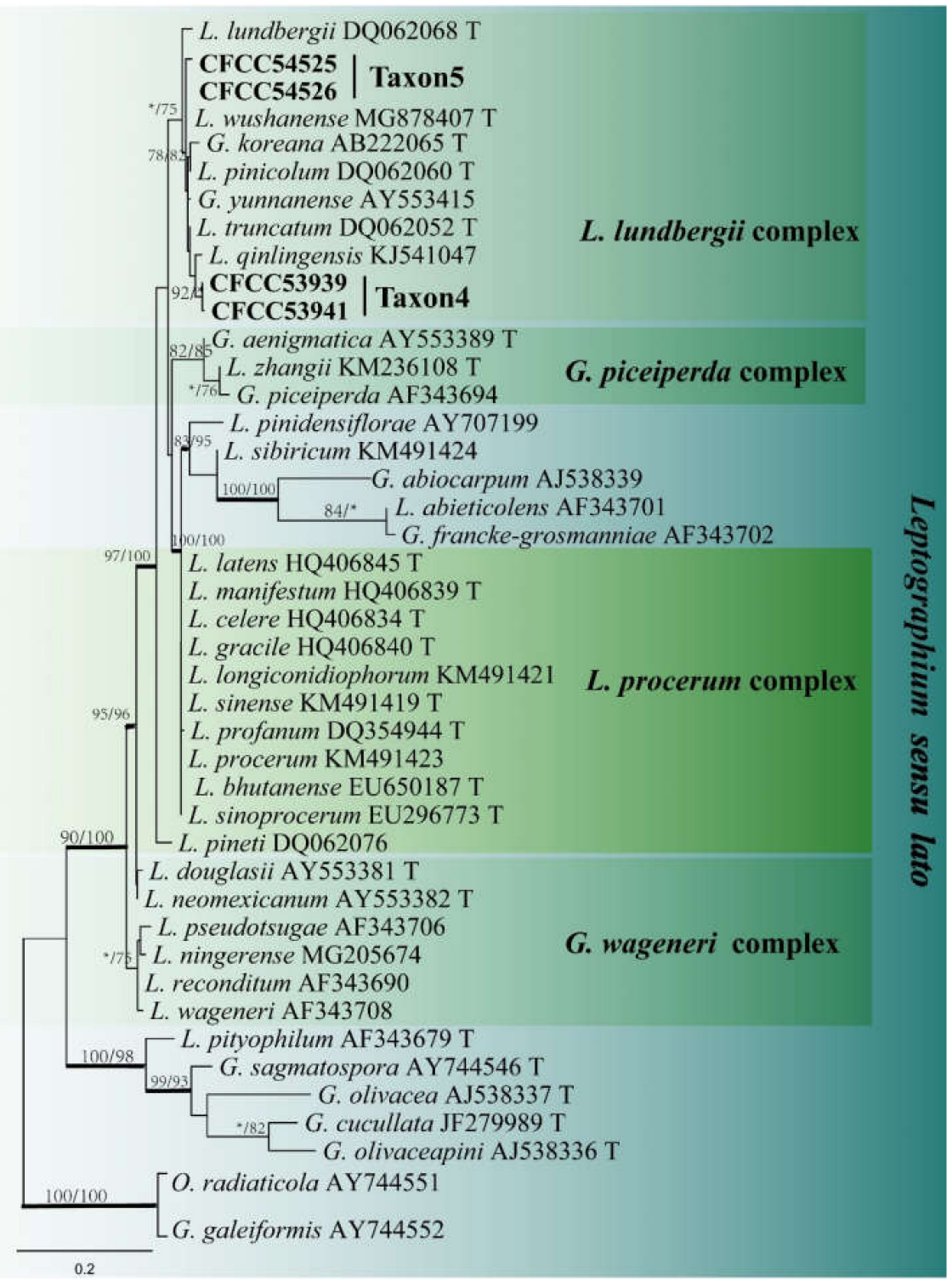

Figure 4. ML tree of Leptographium sensu lato (Taxa 4 and 5) generated from the ITS2-LSU sequence data. Novel sequences obtained in this study are presented in bold typeface. Bold branches indicate posterior probability values $\geq 0.9$. Bootstrap values $\geq 70 \%$ for ML and MP are indicated above branches. Bootstrap values $<70 \%$ are indicated by ${ }^{*}$. Strains representing ex-type sequences are marked with ' $\mathrm{T}$ '.

MycoBank: MB838528.

Description: Sexual state not observed.

Asexual morph: leptographium-like and hyalorhinocladiella-like.

Leptographium-like. Conidiophores erect, macronematous, mononematous, arising directly from the mycelium, (100.5-) 115.9-219.1 (-302.8) $\mu \mathrm{m}$ long, differentiated into a stipe and a conidiogenous apparatus. Stipes cylindrical, straight, 1-4 septate, constricted at septa, brown to dark brown, (17.1-) 27.5-109.2 (-203.7) $\mu \mathrm{m}$ long, (1.8-) 3.3-6.3 (-7.8) $\mu \mathrm{m}$ in diameter; conidiogenous apparatus (14.0-) 25.6-66.7 (-104.4) $\mu \mathrm{m}$ long, with 2-3 series 
of cylindrical branches; primary branch cylindrical, pale brown, smooth, (12.0-) 14.4-35.8 $(-46.1) \times(2.1-) 3.1-4.7(-6.1) \mu \mathrm{m}$; conidiogenous cells cylindrical, discrete, hyaline, (6.0-) 10.2-22.6 (-32.1) $\mu \mathrm{m}$ in length, (1.5-) 2.1-4.0 (-5.4) $\mu \mathrm{m}$ wide; conidia holoblastic, hyaline, single-celled, aseptate, oblong to obovoid, clavate, (5.3-)7.2-11.7 (-14.7) $\times(3.3-) 3.9-5.9$ $(-6.8) \mu \mathrm{m}$.

Hyalorhinocladiella-like: conidiophores arising directly from the mycelium, simple branched, macronematous, or semi-macronematous, mononematous, the ultimate branched bearing conidiogenous cells; conidiogenous cells septate, hyaline, think-walled, rounded apex, (21.4-) 26.5-78.1 (-105.8) × (1.23-) 1.3-2.7 (-4.5) $\mu \mathrm{m}$; conidia hyaline, smooth, singlecelled, aseptate, elliptical to obovoid with truncate base and rounded apex, (3.2-) 4.5-7.7 $(-8.8) \times(1.8-) 2.4-4.4(-5.16) \mu \mathrm{m}$.

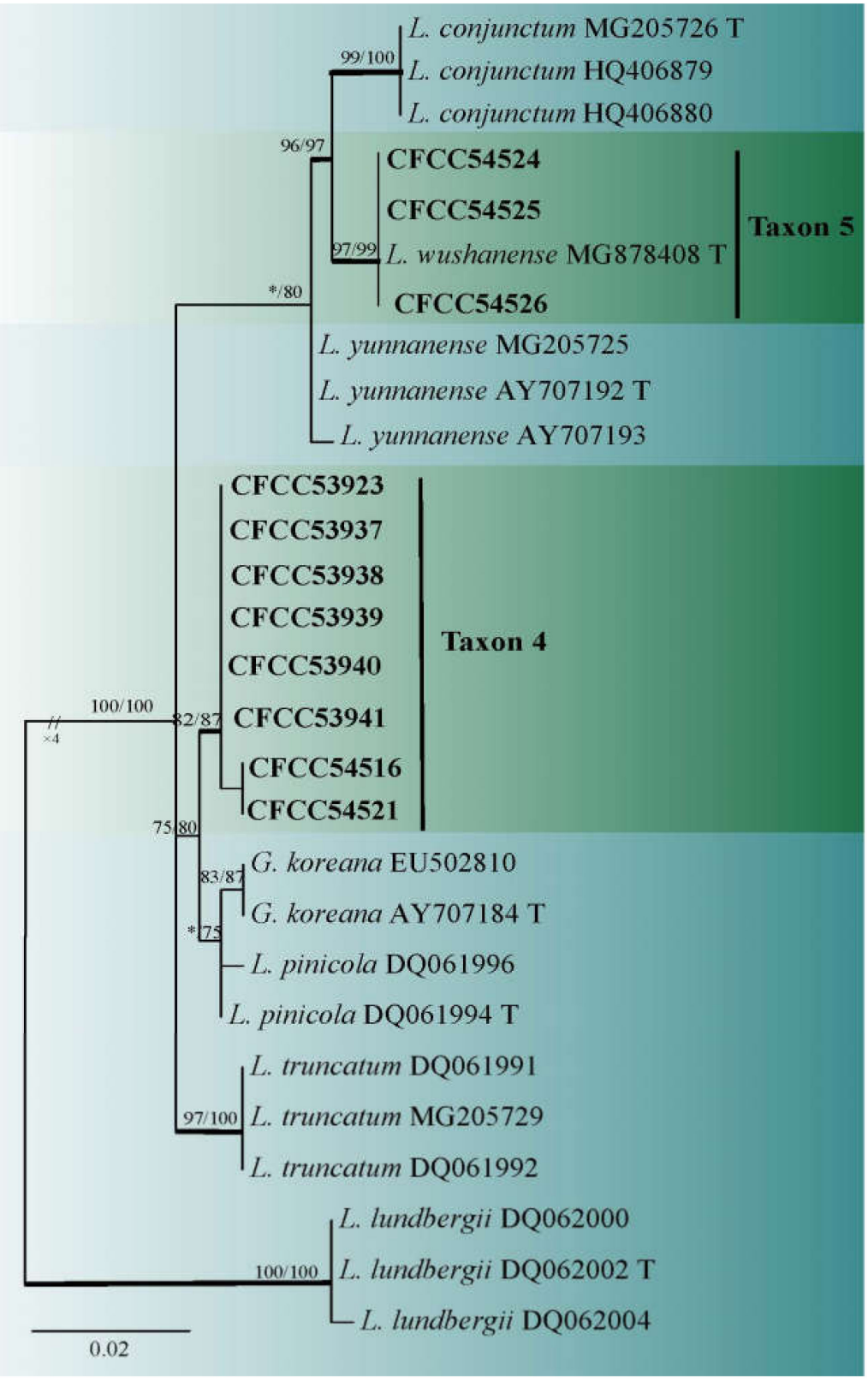

Figure 5. ML tree of L. lundbergii complex (Taxa 4 and 5) generated from the TUB2 sequence data. Novel sequences obtained in this study are presented in bold typeface. Bold branches indicate posterior probability values $\geq 0.9$. Bootstrap values $\geq 70 \%$ for ML and MP are indicated above branches. Bootstrap values $<70 \%$ are indicated by *. Strains representing ex-type sequences are marked with ' $\mathrm{T}$ '. 


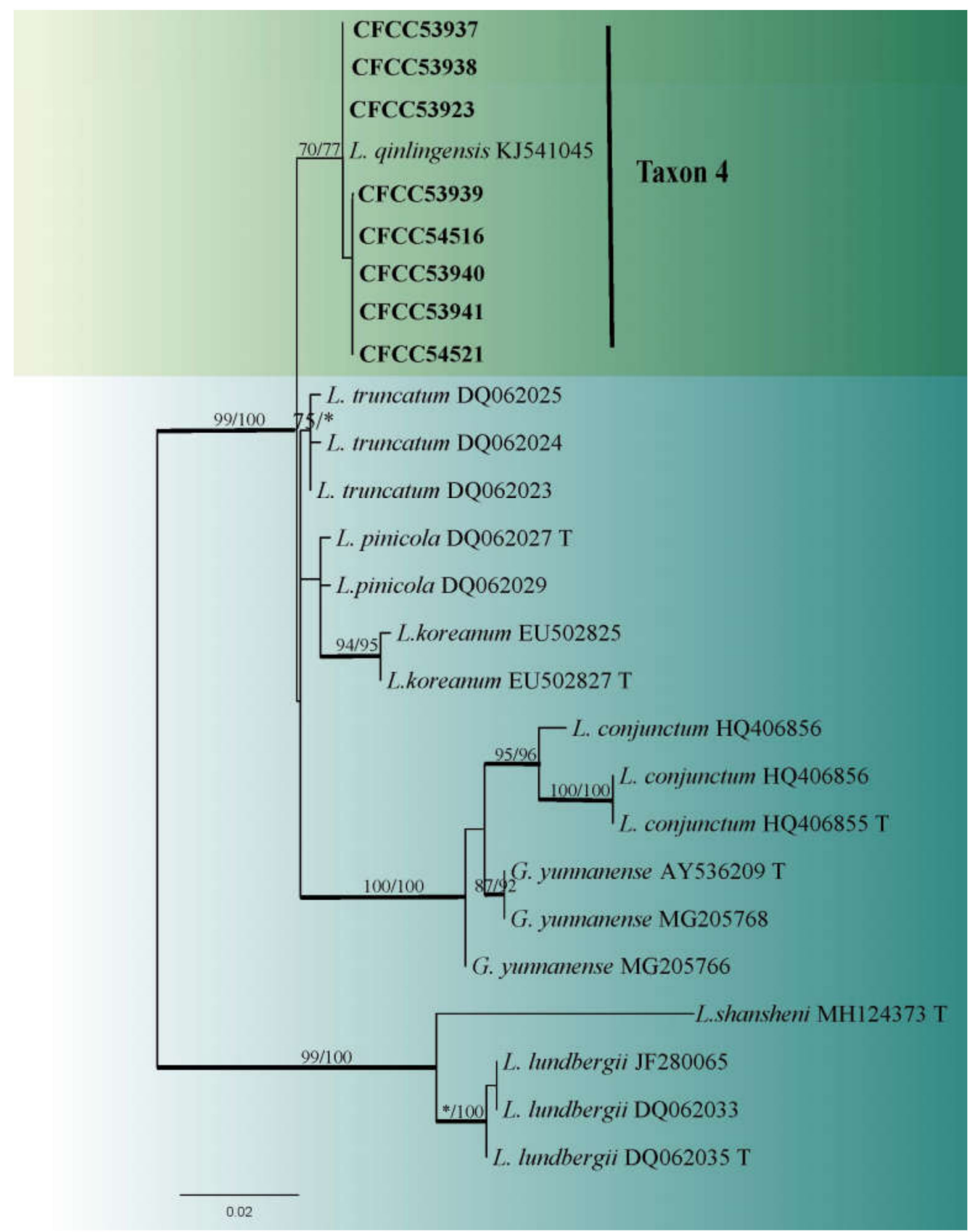

Figure 6. ML tree of L. lundbergii complex (Taxon 4) generated from the TEF1- $\alpha$ sequence data. Novel sequences obtained in this study are presented in bold typeface. Bold branches indicate posterior probability values $\geq 0.9$. Bootstrap values $\geq 70 \%$ for ML and MP are indicated above branches. Bootstrap values $<70 \%$ are indicated by *. Strains representing ex-type sequences are marked with ' $T$ '.

Culture characteristics: Colonies grew rapidly on 2\% MEA, attaining a $90 \mathrm{~mm}$ diameter after five days at $25{ }^{\circ} \mathrm{C}$ in the dark, accounting for a daily growth rate up to $20 \mathrm{~mm}$. Colonies have a smooth margin, radial hyphae, curved shape, initially hyaline, discoloration progressing to olivaceous from the center of the colonies to the margin. The optimum growth temperature is $25^{\circ} \mathrm{C}$; however, growth can occur from $5^{\circ} \mathrm{C}$ to $35^{\circ} \mathrm{C}$.

Known substrate and hosts: Galleries and adults of Dendroctonus armandi in Pinus armandii.

Known insect vectors: Dendroctonus armandi.

Known distribution: Shaanxi, Gansu and Hubei provinces, China. 
Additional specimens examined: CHINA, Gansu Province, Dangchun Forest Farm, galleries and adults of Dendroctonus armandi in Pinus armandii, August 2018, TT Wang, CFCC 53937 = CXY2510, CFCC53938 = CXY2511, CFCC 53923 = CXY2512, CFCC $53939=$ CXY2513, CFCC 53940 = CXY2514; CHINA, Shaanxi Province, Foping County, galleries and adults of Dendroctonus armandi in Pinus armandii, May to July 2019, TT Wang, CFCC 54521 = CXY2541, CFCC 54516 = CXY2542.

Notes: Leptographium qinlingense was first isolated from $D$. armandi which infects $P$. armandii in China [24]. In this study, the strain CFCC53941 was isolated from exactly the same vector and host as the first reported of L. qinlingense. Thus, it was designated as the neotype herein. No differences were observed in the cultures or morphological characteristics between the recently collected neotype and that in the first reported article. Measurements of the asexual structures were consistent with previous descriptions of $L$. qinlingense (Figure 10).

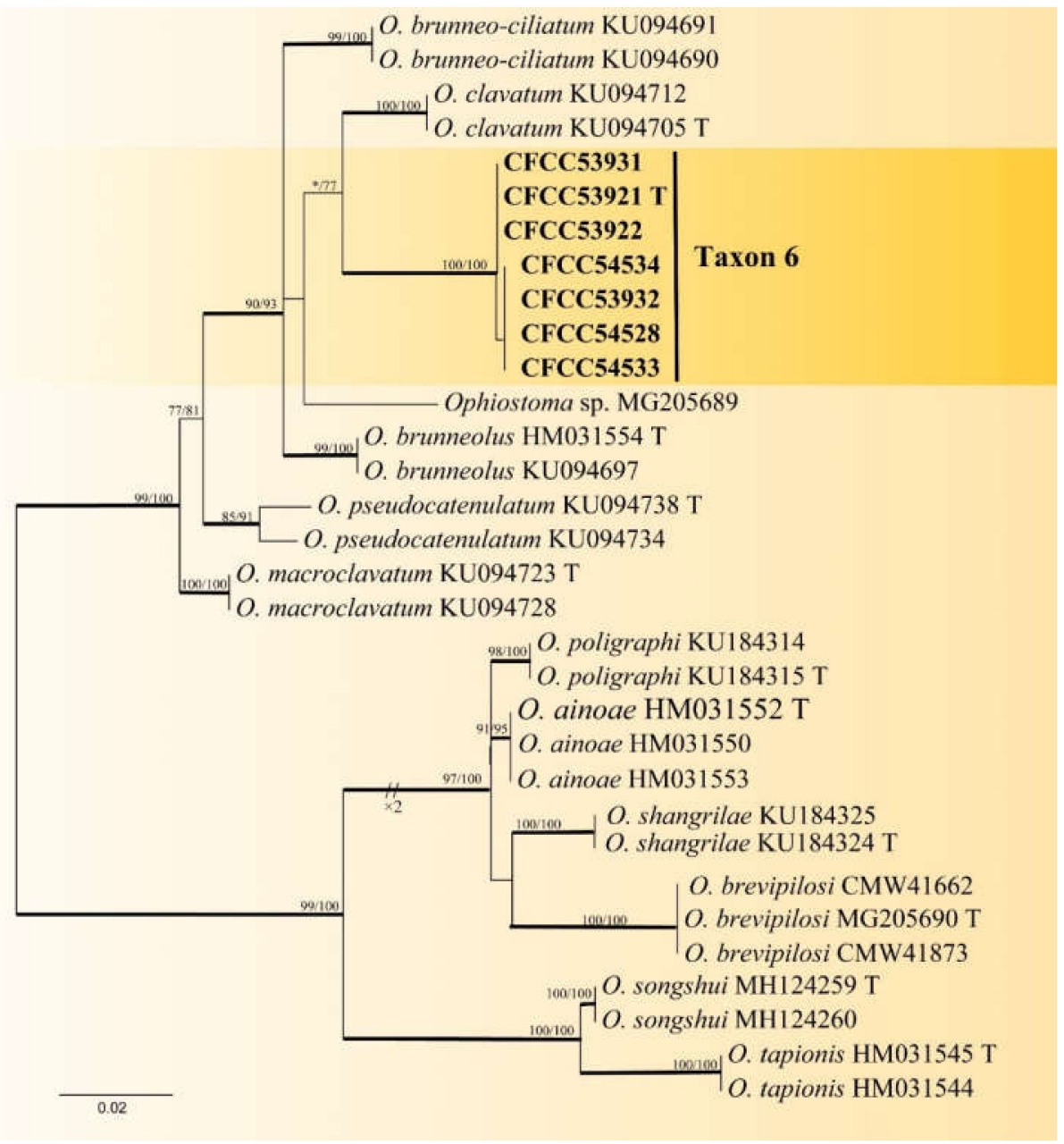

Figure 7. ML tree of O. clavatum complex (Taxon 6) generated from the combined (ITS + TUB2) sequence data. Novel sequences obtained in this study are presented in bold typeface. Bold branches indicate posterior probability values $\geq 0.9$. Bootstrap values $\geq 70 \%$ for ML and MP are indicated above branches. Bootstrap values $<70 \%$ are indicated by *. Strains representing ex-type sequences are marked with ' $\mathrm{T}$ '. 


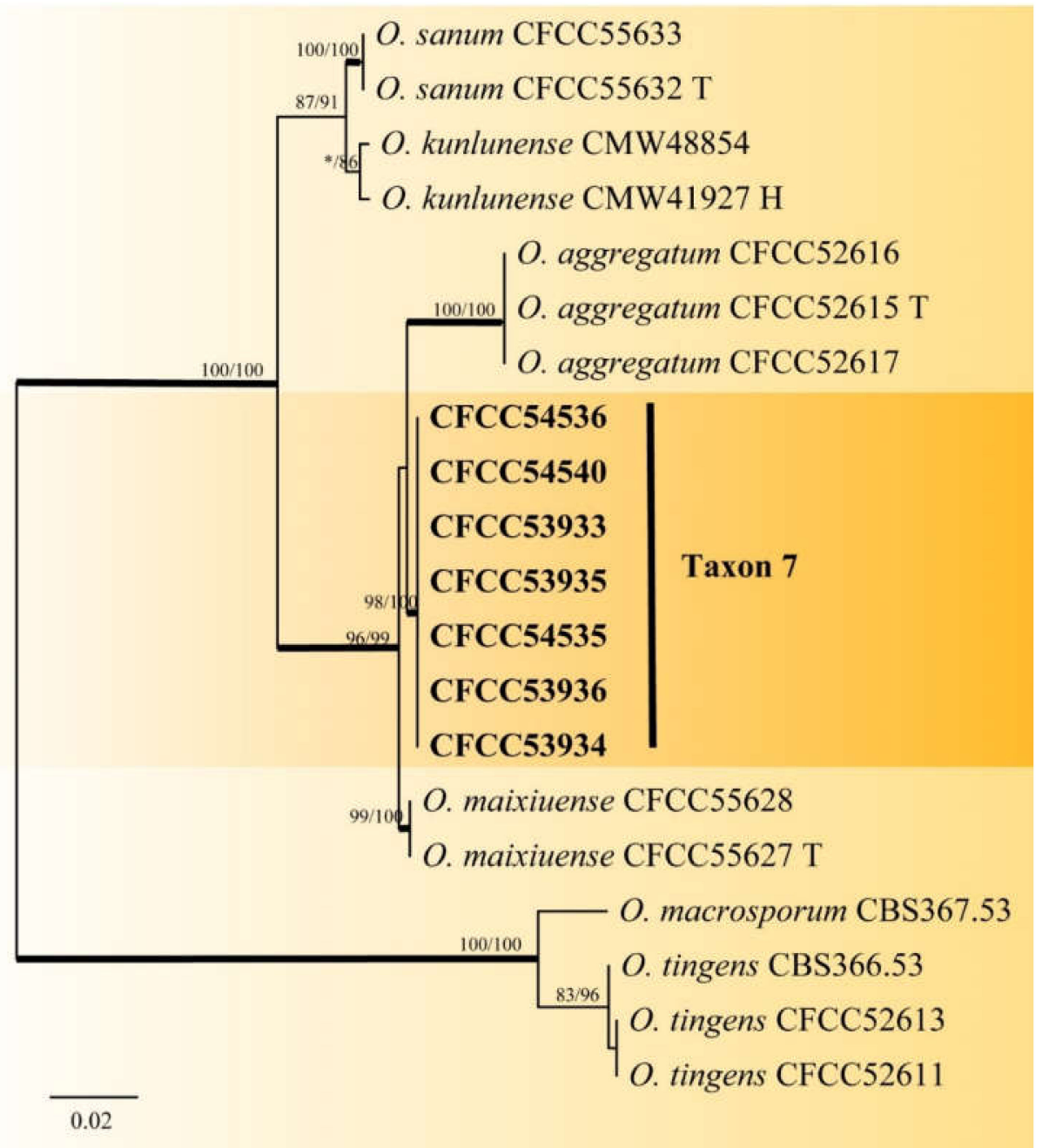

Figure 8. ML tree of Taxon 7 generated from the TUB2 sequence data. Novel sequences obtained in this study are presented in bold typeface. Bold branches indicate posterior probability values $\geq 0.9$. Bootstrap values $\geq 70 \%$ for ML and MP are indicated above branches. Bootstrap values $<70 \%$ are indicated by *. Strains representing ex-type sequences are marked with ' $\mathrm{T}$ '.

Leptographium qinlingense is characterized by a leptographium-like and hyalorhinocladiellalike asexual morphs. It is closely related to G. koreana, L. pinicola, and L. truncatum based on ITS2-LSU, TUB2, and TEF1- $\alpha$ genetic phylogeny (Figures 5 and 6). Within the L. lundbergii complex, L. qinlingense is the sole species containing two asexual morphs (Figure 10). Grosmannia koreana is the sole species with a sexual morph [44]. Moreover, the four species differ in terms of the leptographium-like morph spore size. Specifically, the conidia of L. qinlingense $(4.5-7.7 \mu \mathrm{m})$ are longer than that of L. pinicola, $(3-5 \mu \mathrm{m})$ and either longer than G. koreana $(3-10 \mu \mathrm{m})$, yet shorter than L. truncatum $(7-11 \mu \mathrm{m})$ [44-46]. While $L$. qinlingense is native and endemic to China's mainland, the remaining three species of the L. lundbergii complex are widely distributed in the North temperate hemisphere (Canada, China, England, Korea, and the USA) and the southern hemisphere (New Zealand and South Africa). Furthermore, these four species are associated with bark beetle infestation of conifers [45-47]. 

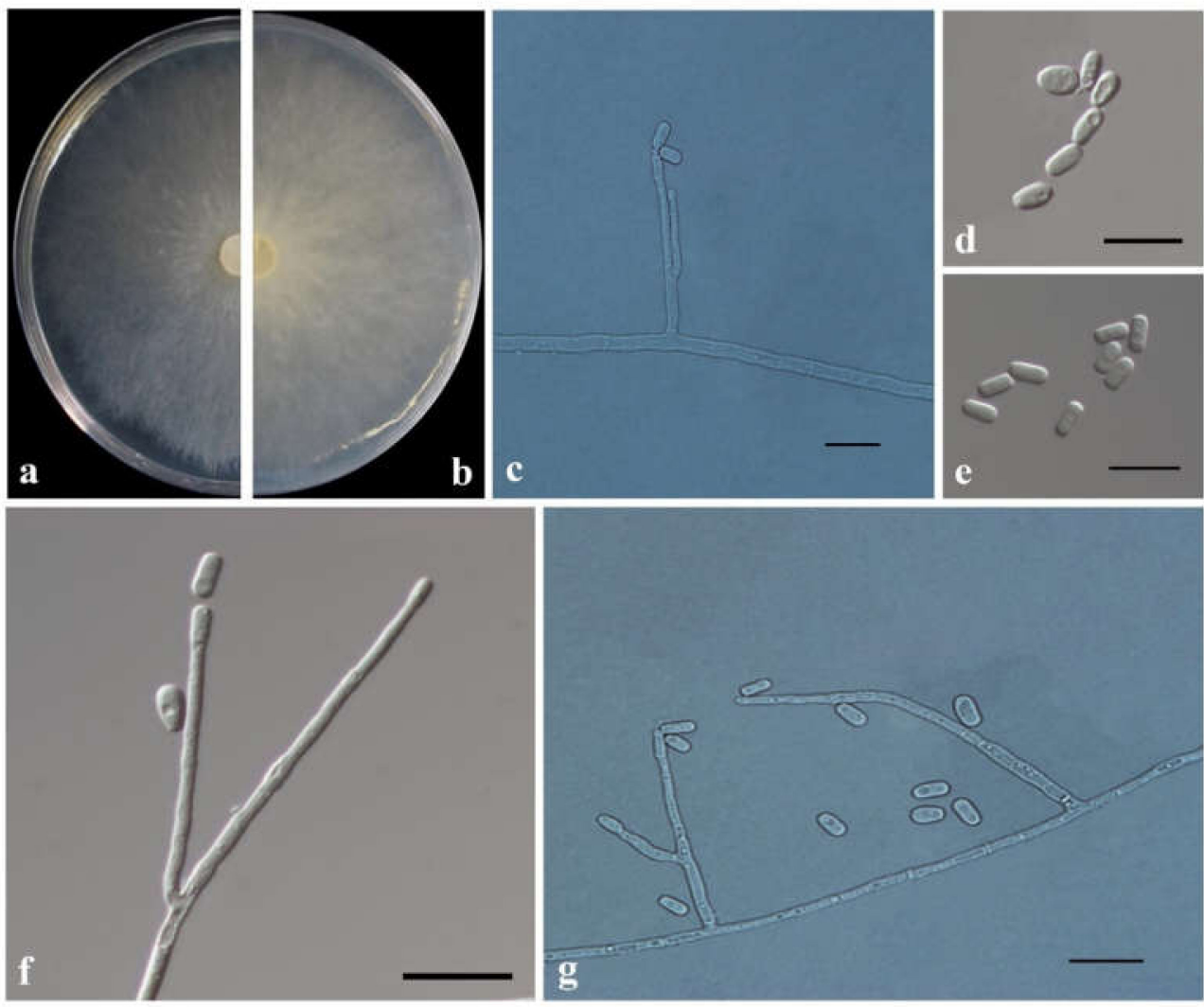

Figure 9. Morphological characteristics of Graphilbum parakesiyea. (a,b) Upper and reverse cultures on $2 \%$ MEA 8 days after inoculation. (c-g) Conidiogenous cells of hyalorhinocladiella-like asexual state and conidia. Scale bars: $10 \mu \mathrm{m}(\mathbf{c}-\mathbf{g})$.
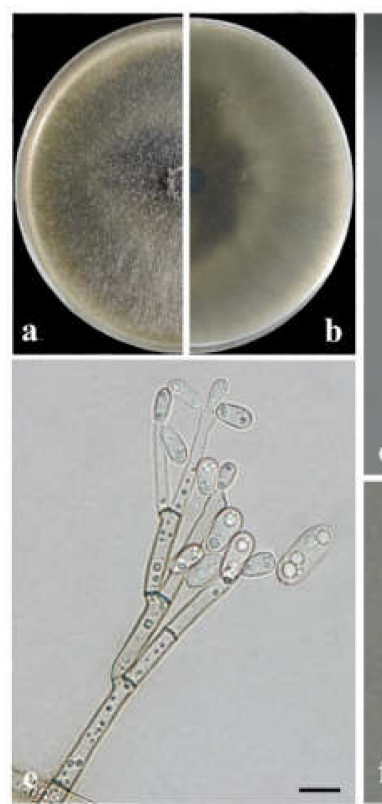

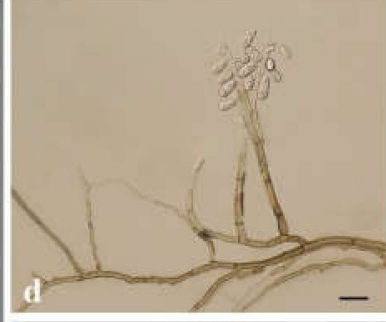

c

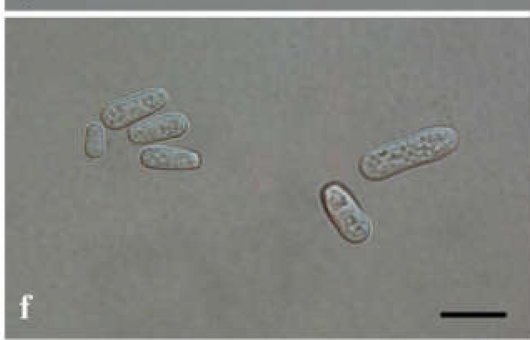

g

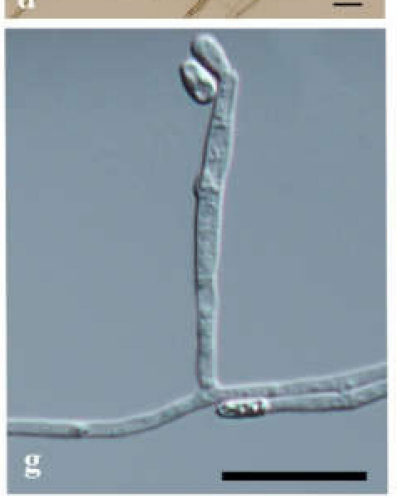

Figure 10. Morphological characteristics of Leptographium qinlingense. $(\mathbf{a}, \mathbf{b})$ Upper and reverse cultures on $2 \%$ MEA 5 days after inoculation; (c-e) Conidiogenous cells of leptographium-like asexual state and conidia; (f,g) Conidiogenous cells of hyalorhinocladiella-like asexual state and conidia. Scale bars: $(\mathbf{d})=20 \mu \mathrm{m} ;(\mathbf{c}, \mathbf{e}-\mathbf{g})=10 \mu \mathrm{m}$. 
Ophiostoma shennongense T. Wang \& Q. Lu sp. nov. Figure 11.

MycoBank: MB838527.

Etymology: 'shennongense' (Latin), referring to the locality.

Type: China, Hubei Province, galleries of Dendroctonus armandi in Pinus armandii, Aug. 2018, TT Wang, holotype CXY2501, ex-type CFCC53921 = CXY2501.

Description: Sexual state not observed.
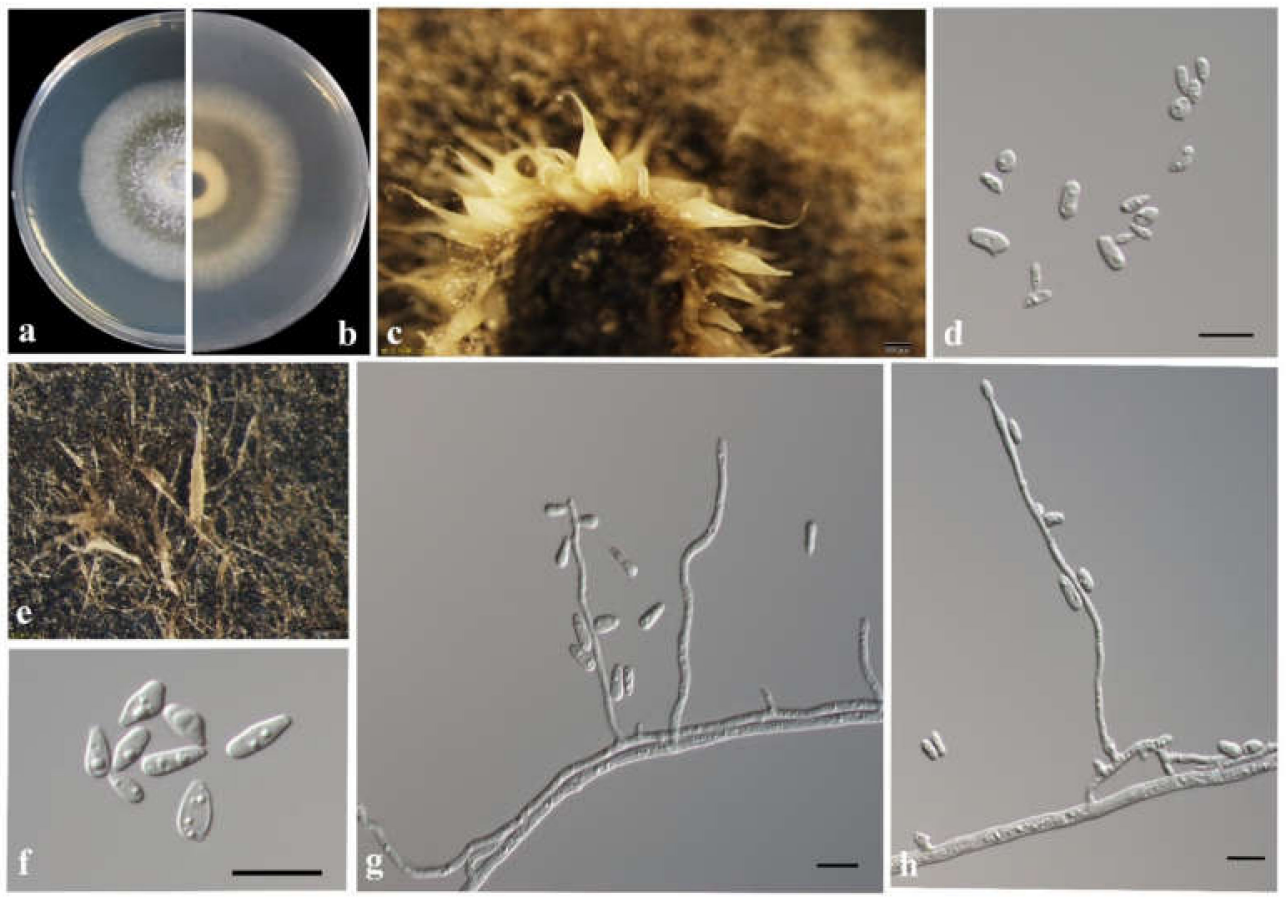

Figure 11. Morphological characteristics of Ophiostoma shennongense. (a,b) Upper and reverse cultures on $2 \%$ MEA 10 days after inoculation. (c,e) Brush-shaped conidiomata. $(\mathbf{d}, \mathbf{f}-\mathbf{h})$ Conidiogenous cells of hyalorhinocladiella-like asexual state and conidia. Scale bars: $(\mathbf{c}, \mathbf{e})=20 \mu \mathrm{m} ;(\mathbf{d}, \mathbf{f}-\mathbf{h})=10 \mu \mathrm{m}$.

Asexual morph: hyalorhinocladiella-like. Conidiophore arising directly from mycelium, simple branched, macronematous or semi-macronematous, mononematous, the ultimate branched bearing numerous conidiogenous cells; conidiogenous cells hyaline, smooth, thin-walled, aseptate, rounded apex, variable in length, (7.1-) 30.0-82.3 (-110.9) × (1.2-) 1.4-2.1 (-2.6) $\mu \mathrm{m}$; conidia holoblastic, hyaline, single-celled, smooth, aseptate, elliptical to obovoid with truncate base and rounded apex, (4.4-) 5.7-7.4 (-8.0) $\times(2.0-)$ 2.2-3.0 $(-3.5) \mu \mathrm{m}$.

Culture characteristics: Colonies grown on 2\% MEA, attaining a $70 \mathrm{~mm}$ diameter after eight days at $25^{\circ} \mathrm{C}$ in the dark, while, with appressed hyphae, colonies are white with a smooth margin, discoloration progresses to pale olivaceous from the center of the colonies to the margin. The optimal temperature is $30{ }^{\circ} \mathrm{C}$; however, growth can begin from $5{ }^{\circ} \mathrm{C}$ to $35^{\circ} \mathrm{C}$.

Known substrate and hosts: Galleries and adults of Dendroctonus armandi in Pinus armandii.

Known insect vectors: Dendroctonus armandi.

Known distribution: Hubei, Shaanxi, and Gansu provinces, China.

Additional specimens examined: CHINA, Hubei Province, Shennongjia Forest Area, galleries and adults of Dendroctonus armandi in Pinus armandii, August 2018, TT Wang, CFCC 53922 = CXY2502; CHINA, Gansu Province, Dangchun Forest Farm, Dendroctonus armandi galleries and adults in Pinus armandii, August 2018, TT Wang, CFCC $53931=$ CXY2503, CFCC 54528 = CXY2534; Shaanxi Province, Foping county, galleries and adults of Dendroctonus armandi in Pinus armandii, May to July, 2019, TT Wang, CFCC $53932=$ 
CXY2505; Shaanxi Province, Huoditang Forest Farm, galleries and adults of Dendroctonus armandi in Pinus armandii, May to July, 2019, TT Wang, CFCC $54534=$ CXY2535, CFCC $54533=$ CXY2536.

Notes: The sole reproductive structure of O. shennongense formed on 2\% MEA was a hyalorhinocladiella-like morph. Ophiostoma shennongense belongs to O. clavatum complex (Figure 7) [48]. The sexual stages of this complex were characterized by brown, spirally coiled ostiolar, hyphae, and cylindrical-to-rectangular ascospores. The asexual stages are hyalorhinocladiella-like to pesotum-like. Ophiostoma shennongense is closely related to O. clavatum based on ITS and TUB2 phylogenetic analyses (Figures 2 and 7). These species differ by their colony color and hyalorhinocladiella-like conidial size. The conidia of O. shennongense (5.7-7.4 $\mu \mathrm{m})$ are larger than in O. clavatum $(4-5 \mu \mathrm{m})[48,49]$. Ophiostoma shennongense colonies are pale olivaceous, whereas the colonies of $O$. clavatum are dark brown to almost black [48].

\section{Discussion}

This study was undertaken to determine the diversity of ophiostomatoid fungi associated with D. armandi infesting P. armandii in the Qinling Mountains of western China. A total of 695 strains of ophiostomatoid fungi were identified from seven species in five genera comprising of four known species, E. vermicola, Gra. pseudormiticum, L. wushanense, and L. qinlingense, as well as a novel neotype strain, as assessed by its type, locality, and combination insect/host (CFCC53941); two novel taxa, Gra. parakesiyea, O. shennongense; and an unidentified Ophiostoma sp. 1.

Among the seven species of ophiostomatoid fungi, O. shennongense was the most frequently isolated species, accounting for an abundance of $78.99 \%$, representing the predominant component of the community associated with D. armandi-P. armandii (Table 3 ), compared to the second most abundant species, L. qinlingense $(8.92 \%)$. Leptographium qinlingense was the first ophiostomatoid species reported to be associated with $D$. armandi, and is currently isolated only from China [24]. This species has previously been shown to exhibit pathogenicity with high virulence $[18,25,50]$. Due to its common occurrence associated with $D$. armandi infesting $P$. armandii, L. qinlingense may have a significant role in the damage observed in D. armandi-infected P. armandii in China [22,50-52].

This study is the second report showing that $L$. wushanense associates with $P$. armandii; however, P. armandii is infected by D. armandi in Shaanxi Province rather than by Tomicus armandii in Yunnan Province [42]. Before this study, only one strain of L. wushanense has been reported from $T$. armandii, which showed occasional association with the beetle and pine. In the present study, L. wushanense was also isolated only at Huoditang Forest Farm out of four investigated sites, showing a limited occurrence (Table 3). The species, therefore, are sporadically located throughout southwestern China and loosely associated with the beetle.

Esteya vermicola and Gra. pseudormiticum were each represented by a single strain. Esteya is a unique genus of Ophiostomataceae, with two species: E. vermicola and E. floridanum. Both species exhibit high infectivity toward the pinewood nematode (Bursaphelenchus xylophilus) by their lunate conidia, and are potentially biocontrol agents against this epidemic pine disease [53-58]. Esteya vermicola was first isolated from Japanese black pine in Taiwan in 1999, and is associated with the pinewood nematode [53]. Since then, eight strains have been recorded worldwide [53-58]. However, although the species appear to be widely distributed, only a single strain was recorded in each of these previous studies. Graphium pseudormiticum was first reported in South Africa and was associated with Orthotomicus erosus [59], subsequently reported in Sweden as associated with Ips typographus, in Austria associated with Tomicus minor [60], and in China associated with Pissodes sp., a mite of Ips acuminatus [43,61].

Although an association between fungi and bark beetles has been observed, the classic theory of reciprocal symbiosis between bark beetles and fungi has been challenged due to the lack of in-depth explanation of the symbiosis mechanism or the existence of 
contradictory research cases. The present study expanded our knowledge of D. armandi and its associated fungi; however, the symbiosis mechanism between ophiostomatoid fungi and $D$. armandi warrant further investigations.

Supplementary Materials: The following are available online at https: / www.mdpi.com/article/ 10.3390/jof8030214/s1, Figure S1: ML tree of Esteya and related taxa (Taxon 1) generated from the combined (LSU+TUB2) sequence data. Novel sequences obtained in this study are presented in bold typeface. Bold branches indicate posterior probability values $\geq 0.9$. Bootstrap values $\geq 70 \%$ for ML and MP are indicated above branches; Figure S2: ML tree of Graphium (Taxon 3) generated from the combined (ITS+tEF1- $\alpha$ ) sequence data. Novel sequences obtained in this study are presented in bold typeface. Bold branches indicate posterior probability values $\geq 0.9$. Bootstrap values $\geq 70 \%$ for ML and MP are indicated above branches.

Author Contributions: Q.L., T.W. and H.W. designed the study; T.W., Y.L. and H.Z. collected the samples; T.W., Y.L. and F.Z. performed DNA extraction and PCR amplification; H.W. analyzed the data and contributed to experiment design; Q.L. and H.W. wrote the manuscript; Q.L., H.W., C.D. and $X . Z$. reviewed and approved the final manuscript. All authors have read and agreed to the published version of the manuscript.

Funding: This study was supported by the National Natural Science Foundation of China (Project No. 32071769, 31770682).

Institutional Review Board Statement: Not applicable for studies involving humans or animals.

Informed Consent Statement: Not applicable for studies involving humans.

Data Availability Statement: All sequence data are available in NCBI GenBank following the accession numbers in the manuscript.

Acknowledgments: We thank Zhongdong Yu from Northwest A\&F University, Jiaxi Yi from Sheng Nong Jia forestry pest natural enemy breeding farm, Hubei and Anmin Li from Xiaolong Mountain Forest Experiment Bureau of Gansu Province, Tianshui for their assistance with insect sample collection.

Conflicts of Interest: The authors declare no conflict of interest.

\section{References}

1. Vega, F.E.; Blackwell, M. Insect-Fungal Associations: Ecology and Evolution; Oxford University Press: New York, NY, USA, 2005.

2. Skelton, J.; Jusino, M.A.; Carlson, P.S.; Smith, K.; Banik, M.T.; Lindner, D.L.; Palmer, M.; Hulcr, J. Relationships among wood-boring beetles, fungi, and the decomposition of forest biomass. Mol. Ecol. 2019, 28, 4971-4986. [CrossRef] [PubMed]

3. Biedermann, P.H.W.; Vega, F.E. Ecology and Evolution of Insect-Fungus Mutualisms. Annu. Rev. Entomol. 2020, 65, 431-455. [CrossRef] [PubMed]

4. Schmidberger, J. Naturgeschichte des Apfelborkenkäfers Apate dispar. Beiträge zur Obstbaumzucht und zur Naturgeschichte der den Obstbäumen Schädlichen Insekten 1836, 4, 213-230.

5. Hartig, T. Ambrosia des Bostrichus dispar. Allg. Forst-Und Jagdztg. 1844, 13, 73.

6. Kile, G.A. Plant diseases caused by species of Ceratocystis sensu stricto and Chalara. In Ceratocystis and Ophiostoma: Taxonomy, Ecology and Pathogenicity; Wingfield, M.J., Seifert, K.A., Webber, J., Eds.; APS Press: St. Paul, MN, USA, 1993 ; pp. $173-184$.

7. Kirisits, T. Fungal associates of European bark beetles with special emphasis on the ophiostomatoid fungi. In Bark and Wood Boring Insects in Living Trees in Europe, A Synthesis; Lieutier, F., Day, K.R., Battisti, A., Gregoire, J.C., Evans, H.F., Eds.; Kluwer Academic Publishers: Dordrecht, The Netherlands, 2004; pp. 181-235.

8. Kirisits, T. Dutch Elm Disease and Other Ophiostoma Diseases; CAB International: Wallingford, UK, 2013 ; pp. $256-282$.

9. Lu, M.; Wingfield, M.J.; Gillette, N.; Sun, J.H. Do novel genotypes drive the success of an invasive bark beetle-fungus complex? Implications for potential reinvasion. Ecology 2011, 92, 2013-2019. [CrossRef]

10. Bracewell, R.R.; Vanderpool, D.; Good, J.M.; Six, D. Cascading speciation among mutualists and antagonists in a tree-beetle-fungi interaction. Proc. R. Soc. B 2018, 285, 20180694. [CrossRef]

11. Hulcr, J.; Stelinski, L.L. The Ambrosia Symbiosis: From Evolutionary Ecology to Practical Management. Annu. Rev. Entomol. 2017, 62, 285-303. [CrossRef]

12. Biedermann, P.H.W.; Rohlfs, M. Evolutionary feedbacks between insect sociality and microbial management. Curr. Opin. Insect Sci. 2017, 22, 92-100. [CrossRef]

13. Li, H.; Young, S.E.; Poulsen, M.; Currie, C.R. Symbiont-mediated digestion of plant biomass in fungus-farming insects. Annu. Rev. Entomol. 2020, 66, 297-316. [CrossRef] 
14. Li, X.J.; Gao, J.M.; Chen, H.; Zhang, A.L. Toxins from a symbiotic fungus, Leptographium qinlingensis associated with Dendroctonus armandi and their in vitro toxicities to Pinus armandii seedlings. Eur. J. Plant Pathol. 2012, 134, 239-247. [CrossRef]

15. Cai, B.H. The distribution characteristics of bark beetles and stem-boring pests in China. Shaanxi For. Sci. Technol. 1980, 1, 1-3.

16. Chen, H.; Tang, M.; Ye, H.M. Niche of bark beetles within Pinus armandii ecosystem in inner Qinling Mountains. Sci. Silvae Sin. 1999, 35, 40-44.

17. Zhang, Z.Y.; Cha, Y.P.; Wang, S.M. Bionomics of Dendroctonus armandi in Shennongjia forestry district. For. Pest Dis. 2015, 34, 1-4.

18. Tang, M.; Chen, H. Effect of symbiotic fungi of Dendroctonus armandi on host trees. Sci. Silvae Sin. 1999, 35, 63-66.

19. Hong, C.; Zeng, B.; Zha, Y.; Hua, X.; Wang, S.; Chen, J. Study on Dendroctonus armandi Diffusion Regular Pattern in Shennongiia Forestry District. Hubei For. Sci. Technol. 2017, 4, 231.

20. Guerrero, R.; Margulis, L.; Berlanga, M. Symbiogenesis: The holobiont as a unit of evolution. Int. Microbiol. $2013,16,133-143$.

21. Hulcr, J.; Barnes, I.; De Beer, Z.W.; Duong, T.A.; Gazis, R.; Johnson, A.J.; Jusino, M.A.; Kasson, M.T.; Li, Y.; Lynch, S.; et al. Bark beetle mycobiome: Collaboratively defined research priorities on a widespread insect-fungus symbiosis. Symbiosis 2020, 81, 101-113. [CrossRef]

22. Xie, S.A.; Shu, L.J.; Axel, S.; Ding, Y.; Hou, Q.S.; Cai, M. Anatomical characteristics in xylem tissue of Pinus armandii infected by the bark beetle Dendroctonus armandi (Coleoptera: Scolytidae) and its associated blue-stain fungus Ceratocystis polonica. Acta Entomol. Sin. 2008, 51, 1327-1333.

23. Skelton, J.; Jusino, M.A.; Li, Y.; Bateman, C.; Thai, P.H.; Wu, C.X.; Lindner, D.L.; Hulcr, J. Detecting symbioses in complex communities: The Fungal Symbionts of Bark and Ambrosia Beetles Within Asian Pines. Microb. Ecol. 2018, 76, 839-850. [CrossRef]

24. Tang, M.; Chen, H.; Zhao, J.P.; Zhu, C.J. Leptographium qinlingensis sp. nov. associated with Dendroctonus armandi in Pinus armandii. J. Huazhong Central China Agric. Univ. 2004, 23, 5-6.

25. Hu, X.; Li, M.; Chen, H. Community structure of gut fungi during different developmental stages of the Chinese white pine beetle (Dendroctonus armandi). Sci. Rep. 2015, 5, 8411. [CrossRef] [PubMed]

26. Jacobs, K.; Wingfield, M.J. Leptographium Species: Tree Pathogens, Insect Associates and Agents of Blue-Stain; American Phytopathological Society Press: St Paul, MN, USA, 2001; pp. 164-167.

27. Marin, M.; Preisig, O.; Wingfield, B.D.; Kirisits, T.; Wingfield, M.J. Phenotypic and DNA sequence data comparisons reveal three discrete species in the Ceratocystis polonica species complex. Mycol. Res. 2005, 109, 1137-1148. [CrossRef] [PubMed]

28. Marincowitz, S.; Duong, T.A.; Taerum, S.J.; de Beer, Z.W.; Wingfield, M.J. Fungal associates of an invasive pine-infesting bark beetle, Dendroctonus valens, including seven new Ophiostomatalean fungi. Pers.-Mol. Phylogeny Evol. Fungi 2020, 45, 177-195. [CrossRef] [PubMed]

29. De Beer, Z.W.; Wingfield, M.J. Emerging lineages in the Ophiostomatales. In The Ophiostomatoid Fungi: Expanding Frontiers; Seifert, K.A., de Beer, Z.W., Wingfield, M.J., Eds.; CBS-KNAW Fungal Biodiversity Centre: Utrecht, The Netherlands, 2013 ; pp. 21-46.

30. Seifert, K.A.; Webber, J.F.; Wingfield, M.J. Methods for Studying Species of Ophiostoma and Ceratocystis. In Ceratocystis and Ophiostoma: Taxonomy, Ecology and Pathogenicity; The American Phytopathological Society Press: St. Paul, MN, USA, 1993; pp. 255-259.

31. Rayner, R.W. A Mycological Colour Chart; CMI: Egham, UK; British Mycological Society: London, UK, 1970.

32. White, T.J.; Bruns, T.; Lee, S.; Taylor, J. Amplification and direct sequencing of fungal ribosomal RNA genes for phylogenetics. In PCR Protocols: A Guide to Methods and Application; Innis, M.A., Gelfand, D.H., Sninsky, J.J., White, T.J., Eds.; Academic Press: San Diego, CA, USA, 1990; pp. 315-322.

33. Vilgalys, R.; Hester, M. Rapid genetic identification and mapping of enzymatically amplified ribosomal DNA from several Cryptococcus species. J. Bacteriol. 1990, 172, 4238-4246. [CrossRef]

34. Glass, N.L.; Donaldson, G.C. Development of primer sets designed for use with the PCR to amplify conserved genes from filamentous ascomycetes. Appl. Environ. Microbiol. 1995, 61, 1323-1330.

35. Jacobs, K.; Bergdahl, D.R.; Wingfield, M.J.; Halik, S.; Seifert, K.A.; Bright, D.E.; Wingfield, B.D. Leptographium wingfieldii introduced into North America and found associated with exotic Tomicus piniperda and native bark beetles. Mycol. Res. 2004, 108, 411-418. [CrossRef]

36. Katoh, K.; Standley, D.M. MAFFT multiple sequence alignment software version 7: Improvements in performance and usability. Mol. Biol. Evol. 2013, 30, 772-780. [CrossRef]

37. Stamatakis, A. RAxML-VI-HPC: Maximum likelihood-based phylogenetic analyses with thousands of taxa and mixed models. Bioinformatics 2006, 22, 2688-2690. [CrossRef]

38. Swofford, D.L. PAUP*: Phylogenetic Analysis Using Parsimony; Version 4; Sinauer Associates: Sunderland, MA, USA, 2003.

39. Ronquist, F.; Huelsenbeck, J.P. MrBayes 3: Bayesian phylogenetic inference under mixed models. Bioinformatics 2003, 19, 1572-1574. [CrossRef]

40. De Beer, Z.W.; Duong, T.A.; Wingfield, M.J. The divorce of Sporothrix and Ophiostoma: Solution to a problematic relationship. Stud. Mycol. 2016, 83, 165-191. [CrossRef]

41. De Beer, Z.W.; Seifert, K.A.; Wingfield, M.J. A nomenclator for ophiostomatoid genera and species in the Ophiostomatales and Microascales. In The Ophiostomatoid Fungi: Expanding Frontiers; Seifert, K.A., de Beer, Z.W., Wingfield, M.J., Eds.; CBS-KNAW Fungal Biodiversity Centre: Utrecht, The Netherlands, 2013; pp. 245-322.

42. Pan, Y.; Lu, J.; Zhou, X.D.; Chen, P.; Zhang, H.; Ye, H. Leptographium wushanense sp. nov. associated with Tomicus armandii on Pinus armandii in Southwestern China. Mycoscience 2018, 61, 43-48. [CrossRef] 
43. Chang, R.L.; Duong, T.A.; Taerum, S.J.; Wingfield, M.J.; Zhou, X.D.; de Beer, Z.W. Ophiostomatoid fungi associated with conifer-infesting beetles and their phoretic mites in Yunnan, China. MycoKeys 2017, 115, 317-318. [CrossRef]

44. Masuya, H.; Kim, J.J.; Wingfield, M.J.; Yamaoka, Y.; Kim, G.H. Discovery and description of a teleomorph for Leptographium koreanum. Mycotaxon 2005, 94, 159-173.

45. Jacobs, K.; Solheim, H.; Wingfield, B.D.; Wingfield, M.J. Taxonomic re-evaluation of Leptographium lundbergii based on DNA sequence comparisons and morphology. Myco. Res. 2005, 109, 1149-1161. [CrossRef]

46. Kim, J.J.; Lim, Y.W.; Breuil, C.; Wingfield, M.; Zhou, X.D.; Kim, G.H. A new Leptographium species associated with Tomicus piniperda infesting pine logs in Korea. Mycol. Res. 2005, 109, 275-284. [CrossRef]

47. Lu, Q.; Decock, C.; Zhang, X.Y.; Maraite, H. Ophiostomatoid fungi (Ascomycota) associated with Pinus tabuliformis infested by Dendroctonus valens (Coleoptera) in northern China and an assessment of their pathogenicity on mature trees. Antonie Van Leeuwenhoek 2009, 96, 275-293. [CrossRef]

48. Linnakoski, R.; Jankowiak, R.; Villari, C.; Kirisits, T.; Wingfieldet, M.J. The Ophiostoma clavatum species complex: A newly defined group in the Ophiostomatales including three novel taxa. Antonie Van Leeuwenhoek 2016, 109, 987-1018. [CrossRef]

49. Mathiesen, A. Einige neue Ophiostoma-arten in Schweden. Sven Bot. Tidskr 1951, 45, 203-232.

50. Chen, H.; Tang, M.; Zhu, C.J.; Hu, J.J. The Enzymes in the Secretions of Dendroctonus armandi (Scolytidae) and Their Symbiotic Fungus of Leptographium qinlingensis. Sci. Silvae Sin. 2004, 40, 123-126.

51. Pu, X.J.; Chen, H.; Wang, S.J. Influences of Leptographium qinglingensis on Metabolism of Pinus armandi. J. Northwest For. Univ. 2008, 23, 109-112.

52. Pham, T.; Chen, H.; Yu, J.; Dai, L.; Zhang, R.; Vu, T.Q.T. The Differential effects of the blue-stain fungus Leptographium qinlingensis on monoterpenes and sesquiterpenes in the stem of Chinese white pine (Pinus armandii) saplings. Forests 2014, 5, 2730-2749. [CrossRef]

53. Liou, J.Y.; Shih, J.Y.; Tzean, S.S. Esteya, a new nematophagous genus from Taiwan, attacking the pinewood nematode (Bursaphelenchus xylophilus). Mycol. Res. 1999, 103, 242-248. [CrossRef]

54. Kubátová, A.; Novotný, D.; Prášil, K.; Mrácek, Z. The nematophagous hyphomycete Esteya vermicola found in the Czech Republic. Czech Mycol. 2000, 52, 227-235. [CrossRef]

55. Wang, H.M.; Wang, Z.; Liu, F.; Wu, C.X.; Zhang, S.F.; Kong, X.B.; Decock, C.; Lu, Q.; Zhang, Z. Differential patterns of ophiostomatoid fungal communities associated with three sympatric Tomicus species infesting pines in southwestern China, with description of four new species. MycoKeys 2019, 50, 93-133.

56. Wang, X.; Wang, T.; Wang, J.; Guan, T.; Li, H. Morphological, molecular and biological characterization of Esteya vermicola, a nematophagous fungus isolated from intercepted wood packing materials exported from Brazil. Mycoscience 2014, 55, 367-377. [CrossRef]

57. Wang, C.Y.; Fang, Z.M.; Wang, Z.; Gu, J.; Chang, K.S. High infection activities of two Esteya vermicola isolates against pinewood nematode. Afr. J. Microbiol. Res. 2009, 3, 581-584.

58. Li, Y.; Yu, H.; Araújo, J.P.M.; Zhang, X.; Hulcr, J. Esteya floridanum sp. nov.: An Ophiostomatalean Nematophagous Fungus and its Potential to Control the Pine Wood Nematode. Phytopathology 2020, 111, 304-311. [CrossRef]

59. Mouton, M.; Wingfield, M.J.; Van Wyk, P.S.; Van Wyk, P.W.J. Graphium pseudormiticum sp. nov.: A new hyphomycete with unusual conidiogenesis. Mycol. Res. 1994, 98, 1272-1276. [CrossRef]

60. Lackner, M.; de Hoog, G.S. Parascedosporium and its relatives: Phylogeny and ecological trends. IMA Fungus 2011, 2, 39-48. [CrossRef]

61. Paciura, D.; Zhou, X.D.; De Beer, Z.W.; Jacobs, K.; Ye, H.; Wingfield, M.J. Characterisation of synnematous bark beetle-associated fungi from China, including Graphium carbonarium sp. nov. Fungal Divers. 2010, 40, 75-88. [CrossRef] 